This article is licensed under the Creative Commons Attribution-NonCommercial 4.0 International License (CC BY-NC) (http://www.karger.com/Services/OpenAccessLicense). Usage and distribution for commercial purposes requires written permission.

\title{
Elbasvir/Grazoprevir, an Alternative in Antiviral Hepatitis C Therapy in Patients under Amiodarone Treatment
}

\author{
Lina Weiss ${ }^{a, b}$ Kerstin Wustmann ${ }^{c}$ Mariam Semmo ${ }^{d}$ \\ Markus Schwerzmann ${ }^{c}$ Nasser Semmo ${ }^{a}$ \\ ${ }^{a}$ Clinic for Visceral Medicine and Surgery, Department of Hepatology, Inselspital Bern, \\ Bern, Switzerland; ${ }^{b}$ Charité - Universitätsmedizin Berlin, Berlin, Germany; ${ }^{\mathrm{C} D e p a r t m e n t}$ of \\ Cardiology, Inselspital Bern, Bern, Switzerland; ${ }^{d}$ Department of Nephrology, Inselspital \\ Bern, Bern, Switzerland
}

\section{Keywords}

Drug interactions · Antiviral agents · Hepatitis C - Amiodarone

\begin{abstract}
A sofosbuvir/ledipasvir combination is part of a first-line treatment of hepatitis C. However, in patients concurrently treated with amiodarone, cardiac side effects have been described, resulting in an official warning in 2015 by the American Food and Drug Administration and the European Medicines Agency when combining those substances. This deprived numerous hepatitis $C$ patients with concurrent cardiovascular problems of receiving this highly effective treatment. Here we present a treatment alternative with an elbasvir/grazoprevir regimen, based on our successful treatment of a patient under concurrent amiodarone therapy. Our observations indicate that patients treated with amiodarone can finally benefit from effective antiviral therapy.

(C) 2018 The Author(s)

Published by S. Karger AG, Basel
\end{abstract}




\section{Case Reports in Gastroenterology}

Case Rep Gastroenterol 2018;12:92-98

(c) 2018 The Author(s). Published by S. Karger AG, Basel www.karger.com/crg

Weiss et al.: Elbasvir/Grazoprevir, an Alternative in Antiviral Hepatitis C Therapy in

Patients under Amiodarone Treatment

\section{Introduction}

A sofosbuvir/ledipasvir combination is part of a first-line treatment of hepatitis $\mathrm{C}$ with a sustained virological response of around 99\% [1]. However, in patients concurrently treated with amiodarone, bradyarrhythmias and scarcely other arrhythmic disorders have been described [2, 3], resulting in an official warning in 2015 by the American Food and Drug Administration (FDA) and the European Medicines Agency (EMA) when combining those substances $[4,5]$. Until now, patients in whom amiodarone therapy is essential and cannot be discontinued could not benefit from an effective antiviral therapy. Here we present a first case of successful antiviral treatment with elbasvir/grazoprevir under concurrent amiodarone therapy in a patient who had previously shown drug interactions between sofosbuvir/ ledipasvir and amiodarone.

\section{Case Report}

The patient, who was a 52-year-old male of Mongolian origin, had cyanotic congenital heart disease. He was born with a large ventricular septal defect that was not repaired in childhood. Over the years, he developed severe shunt-induced pulmonary hypertension leading to shunt reversal (Eisenmenger syndrome) with a resting oxygen saturation of 85$90 \%$. He was in functional NYHA class II-III and suffered from recurrent sustained supraventricular tachycardia. Therefore, he was under continuous treatment with amiodarone $200 \mathrm{mg} /$ day, metoprolol $75 \mathrm{mg} /$ day, and sildenafil $60 \mathrm{mg} /$ day. From a clinical point of view the patient's cardiovascular symptoms were well controlled with the given medication. Being dependent on both medication and regular medical checkups, he was able to work and lead a more or less normal life.

His further medical record consisted of a chronic hepatitis C (genotype 1B), primary biliary cholangiopathy, condition after hepatitis B and tuberculosis, hypothyroidism, and chronic kidney disease (see Table 1 for an overview). He first presented to our Hepatology Outpatient Clinic in 2013.

For his chronic hepatitis $\mathrm{C}$ he had been treated twice elsewhere with pegylated interferon and ribavirin in 2003 and 2006, but had shown viral relapse both of these times. In December 2015, we intended to treat the patient with a combination of sofosbuvir $400 \mathrm{mg}$ and ledipasvir 60 mg (Harvoni ${ }^{\circledR}$ ). Since the FDA Drug Safety Communication and the EMA had warned about serious bradycardia when amiodarone was combined with sofosbuvircontaining drugs like Harvoni ${ }^{\circledR}$, we wanted the patient to stop amiodarone before and during antiviral therapy. Before the patient was seen by a cardiologist to decide whether amiodarone could be stopped or switched to an alternative drug, the patient took a dose of Harvoni ${ }^{\circledR}$ accidentally at home while still taking amiodarone. He developed symptomatic bradycardia with a heart rate of $30 \mathrm{bpm}$. An emergency physician applied $50 \mu \mathrm{g}$ fentanyl and $1 \mathrm{mg}$ midazolam i.v. and started external provisional pacing. The patient was then admitted to our emergency department by air rescue. At admission, his resting ECG showed sinus arrest. With isoprenaline i.v., he developed a frequency-dependent AV block type II and remained with a bradycardic heart rate. Finally, a temporary pacemaker wire had to be placed in the atrium, despite his markedly increased risk for paradoxical systemic embolism as an Eisen- 


\section{Case Reports in Gastroenterology}

Case Rep Gastroenterol 2018;12:92-98

DOI: $10.1159 / 00048695$

(C) 2018 The Author(s). Published by S. Karger AG, Base www.karger.com/crg

Weiss et al.: Elbasvir/Grazoprevir, an Alternative in Antiviral Hepatitis C Therapy in

Patients under Amiodarone Treatment

menger patient. After 1 day his condition improved and the majority of heartbeats were selftriggered, resulting in a frequency of $61 \mathrm{bpm}$. Two days after hospitalization the temporary pacemaker was removed and the patient was discharged in a stable condition.

Because of the language barrier, the patient's complex heart disease that definitely required continuous amiodarone treatment, and his presentation of highly dangerous drug interactions, we decided against further treatment attempts with an antiviral therapy containing sofosbuvir. Due to a lack of treatment alternatives at that time, we saw him for regular follow-ups to monitor his liver function, FibroScan, and viral activity.

In 2016, a new class of antiviral drugs was approved in Switzerland, amongst others Zepatier ${ }^{\circledR}$ (MSD Merck Sharp \& Dohme AG), a combination of elbasvir, an NS5A inhibitor, and grazoprevir, an NS3/4A protease inhibitor, for oral treatment of chronic hepatitis $\mathrm{C}$ virus (HCV) genotypes 1 and 4 [6].

In the end of 2016, the patient presented with progressive liver disease graded Child A6, MELD 13, demonstrated by elevated liver enzymes (Fig. 1a; Table 2), a FibroScan of $16.5 \mathrm{kPa}, \mathrm{CAP} 300 \mathrm{~dB} / \mathrm{m}$, and an ultrasound showing progressive fibrotic changes in the liver. We conducted a liver biopsy that revealed steatotic and fibrotic parenchyma graded METAVIR A2F3, SAF score S2 A2 F3, the latter score confirming nonalcoholic steatohepatitis. The patient complained about being increasingly tired and about intermittent pain in the upper right quadrant of his abdomen resulting in recurrent sick days and inability to partake in everyday life. Considering these progressive findings and his augmented hepatological risk profile due to his primary biliary cholangiopathy, manifesting with positive AMA-M2 antibodies $(1: 1,280)$, and nonalcoholic steatohepatitis shown in his ultrasound and biopsy, we were urged to reconsider antiviral therapy. Because of his other comorbidities, foremost his kidney disease and hypothyroidism, we decided for a treatment attempt with elbasvir/ grazoprevir. Due to the patient's history of cardiac complications under antiviral treatment, we hospitalized him for 2 days in February of 2017 to introduce the medication under telemetric control while he continued using amiodarone. The surveillance and therapy introduction worked without any incident, demonstrated by stable ECG results, so that the patient was discharged after 2 days.

During the 12-week therapeutic period we did regular follow-ups every 2-3 weeks in close collaboration with the cardiologists. Apart from palpitations uttered by the patient, which were without any ECG correlate, the patient showed an improving general state. He reported being less tired and a decrease in the above-mentioned abdominal pain. Palpitations are described as frequent side effects of Zepatier ${ }^{\circledR}$ by the producer [7], therefore we regarded them as such.

Liver enzymes started to normalize as early as 2 weeks after the beginning of the elbasvir/grazoprevir treatment (Fig. 1a; Table 2). The hepatitis $C$ viremia decreased over the first few weeks, with an undetectable virus content 1 month after therapy induction (Fig. 1c; Table 2). During the first few weeks the patient's kidney values increased but returned to a stable level towards the end of therapy (Fig. 1b; Table 2).

With a sustained virological response 12 weeks after the end of antiviral treatment with elbasvir/grazoprevir, our patient was considered cured of his hepatitis C. With regard to the comorbidities and the complicated history including two viral relapses following interferon therapy and cardiac complications under sofosbuvir, we consider this a big success. 


\section{Case Reports in \\ Gastroenterology}

Case Rep Gastroenterol 2018;12:92-98

(c) 2018 The Author(s). Published by S. Karger AG, Basel www.karger.com/crg

Weiss et al.: Elbasvir/Grazoprevir, an Alternative in Antiviral Hepatitis C Therapy in

Patients under Amiodarone Treatment

\section{Discussion}

The literature gives multiple examples of drug interactions between amiodarone and sofosbuvir-containing drugs like Harvoni ${ }^{\circledR}$ or Sovaldi ${ }^{\circledR}$, with bradyarrhythmias and scarcely other cardiac arrhythmic disorders sometimes even leading to serious life-threatening complications $[2,3]$. Due to recommendations of the FDA and the EMA following these reports not to combine amiodarone with sofosbuvir-containing antiviral treatment regimens [4, 5], many multimorbid patients with cardiac comorbidities accompanying their chronic HCV infection were deprived of a highly effective HCV therapy. Our patient, who was treated with an elbasvir/grazoprevir antiviral regimen while concurrently taking amiodarone, is to our knowledge the first published case of a successful antiviral hepatitis $\mathrm{C}$ treatment alternative in comedication with amiodarone. Since drug interactions are hard to anticipate and not nearly every individual under concurrent amiodarone and sofosbuvir therapy will necessarily develop complications, our treatment strategy needed to be effective in a patient who had previously shown drug interactions. In our case, this was further complicated by social factors such as a massive language barrier and cultural differences as well as numerous comorbidities. This underlines the necessity for social awareness, an individualized treatment approach, and impeccable planning.

Our antiviral therapy approach with elbasvir/grazoprevir under concurrent amiodarone treatment presents a new perspective of successfully treating this group of often highrisk patients. However, in order to avoid serious interactions between drugs as previously seen under sofosbuvir, treatment introduction under telemetric control for the first couple of days is advised until further data for those specific cases are available.

Although no cases of pharmacological interactions with amiodarone for elbasvir/grazoprevir are known and the described interactions between sofosbuvir and amiodarone are most likely caused by a direct cardiotoxic effect of sofosbuvir rather than enzyme interactions [8], a potential risk due to a slight CYP3A4 inhibition by grazoprevir does exist [7, 9]. Grazoprevir in return can be affected by strong CYP3A4 inhibitors [7], and although amiodarone is known to only cause a slight CYP3A4 inhibition, drug interactions are often difficult to anticipate, especially in multimorbid patients [8].

Although widely successful, hepatitis $C$ therapy is still a challenge, especially in patients with multiple comorbidities. Therefore, special care and attention should be paid to drug interactions and individualized treatment strategies.

\section{Statement of Ethics}

The authors have no ethical conflicts to disclose. Informed consent was given by the patient with regard to the use of his medical information.

\section{Disclosure Statement}

The authors declare no conflict of interest regarding the publication of this paper. 


\section{Case Reports in Gastroenterology}

Weiss et al.: Elbasvir/Grazoprevir, an Alternative in Antiviral Hepatitis C Therapy in

Patients under Amiodarone Treatment

\section{References}

-1 Afdhal N, Zeuzem S, Kwo P, Chojkier M, Gitlin N, Puoti M, Romero-Gomez M, Zarski JP, Agarwal K, Buggisch P, Foster GR, Bräu N, Buti M, Jacobson IM, Subramanian GM, Ding X, Mo H, Yang JC, Pang PS, Symonds WT, McHutchison JG, Muir AJ, Mangia A, Marcellin P; ION-1 Investigators: Ledipasvir and sofosbuvir for untreated HCV genotype 1 infection. N Engl J Med 2014;370:1889-1898.

2 Renet S, Chaumais MC, Antonini T, Zhao A, Thomas L, Savoure A, Samuel D, Duclos-Vallée JC, Algalarrondo V: Extreme bradycardia after first doses of sofosbuvir and daclatasvir in patients receiving amiodarone: 2 cases including a rechallenge. Gastroenterology 2015;149:1378-1380.e1. Fontaine H, Lazarus A, Pol S, Pecriaux C, Bagate F, Sultanik P, Boueyre E, Corouge M, Mallet V, ValletPichard A, Sogni P, Duboc D; Cochin Hepatology and Cardiology Group: Bradyarrhythmias associated with sofosbuvir treatment. N Engl J Med 2015;373:1886-1888.

$4 \quad$ FDA Drug Safety Podcast: FDA warns of serious slowing of the heart rate when antiarrhythmic drug amiodarone is used with hepatitis $C$ treatments containing sofosbuvir Harvoni or Sovaldi in combination with another direct acting antiviral drug. https://www.fda.gov/downloads/Drugs/ DrugSafety/UCM439492.pdf (accessed August 17, 2017). European Medicines Agency: EMA recommends avoidance of certain hepatitis C medicines and amiodarone together. http://www.ema.europa.eu/docs/en_GB/document_library/Press_release/ 2015/04/WC500186152.pdf (accessed August 17, 2017). Fellner C: Pharmaceutical approval update. P T 2016;41:162-163. European Medicines Agency: Annex I. Summary of product characteristics. http://www.ema.europa.eu/docs/en_GB/document_library/EPAR_-_Product_Information/human/ 004126/WC500211235.pdf (accessed August 17, 2017).

-8 Back D, Burger D: Interaction between amiodarone and sofosbuvir-based treatment for hepatitis C virus infection: potential mechanisms and lessons to be learned. Gastroenterology 2015;149:13151317.

-9 Vallet-Pichard A, Pol S: Grazoprevir/elbasvir combination therapy for HCV infection. Ther Adv Gastroenterol 2017;10:155-167. 
a

liver values

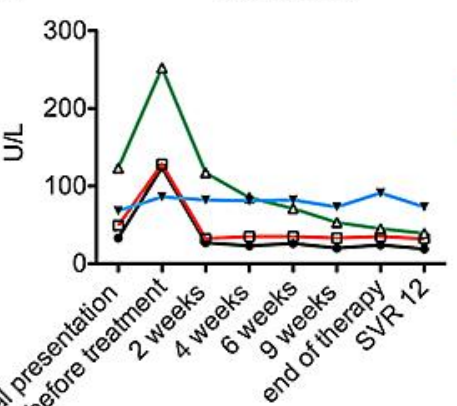

b kidney values

$\rightarrow$ ALT

$\triangle-$ gamma-GT

$\rightarrow$ AP

(C) 2018 The Author(s). Published by S. Karger AG, Basel www.karger.com/crg

Weiss et al.: Elbasvir/Grazoprevir, an Alternative in Antiviral Hepatitis C Therapy in

Patients under Amiodarone Treatment
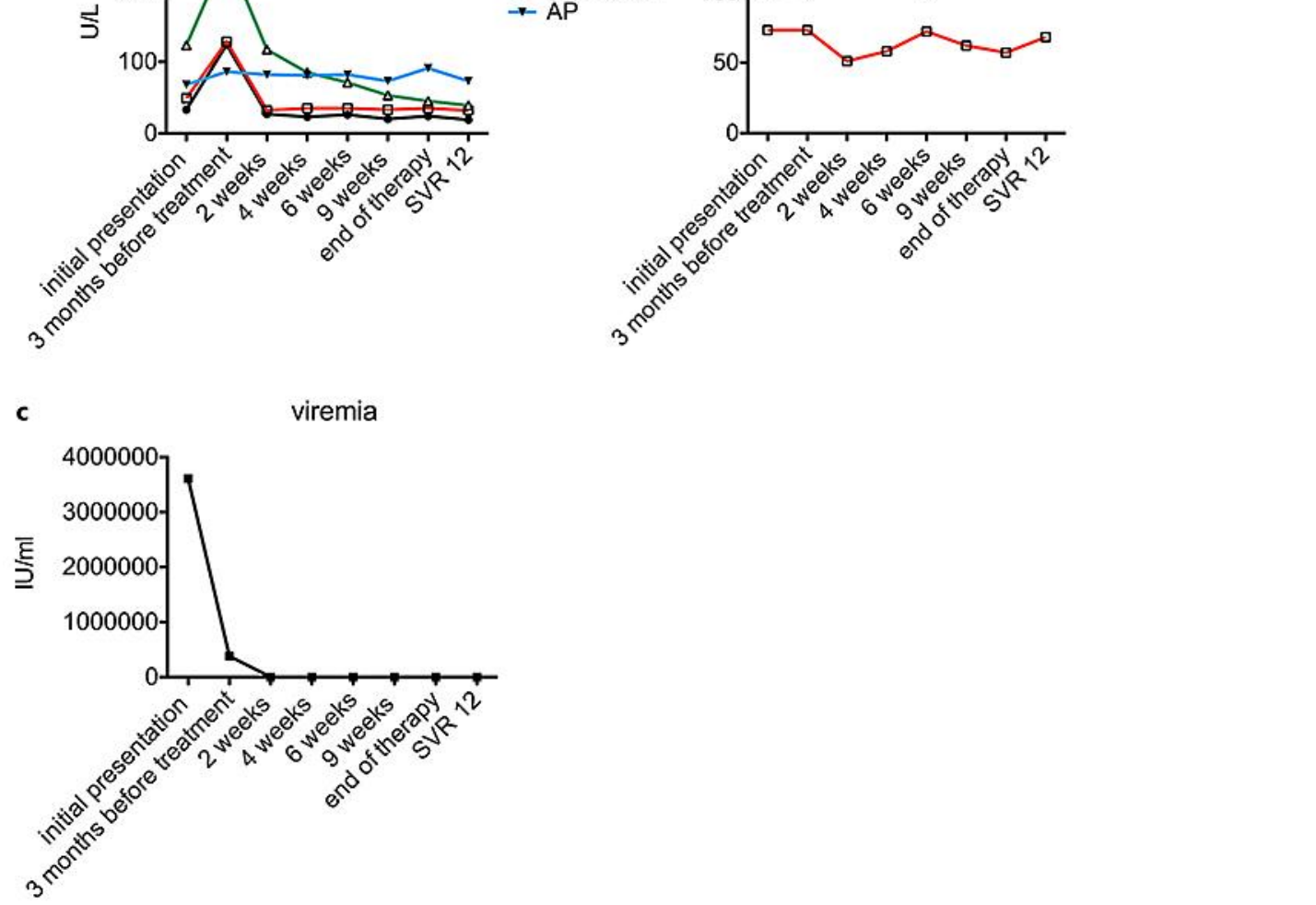

Fig. 1. Overview of the laboratory results at the time of the patient's initial presentation in 2013, the results at the end of 2016 leading to the treatment decision with elbasvir/grazoprevir, during, at the end, and 12 weeks after (SVR 12) elbasvir/grazoprevir treatment. a Overview and development of liver values. b Overview and development of kidney values. c Overview and development of hepatitis $\mathrm{C}$ viremia. 
Table 1. Characteristics of the patient

\begin{tabular}{|c|c|}
\hline Age, years & 52 \\
\hline Sex & male \\
\hline Origin & Mongolian \\
\hline HCV genotype & $1 \mathrm{~B}$ \\
\hline Child/MELD & A6/13 \\
\hline Secondary diagnoses & $\begin{array}{l}\text { nonrestrictive ventricular septal defect, NYHA II-III, Eisenmenger } \\
\text { syndrome; recurrent episodes of AVNRT and AVTR; hypothyroidism; } \\
\text { condition after hepatitis A and B; primary biliary cholangiopathy; } \\
\text { nonalcoholic steatohepatitis; chronic kidney disease KDIGO } 2\end{array}$ \\
\hline Medication & $\begin{array}{l}\text { amiodarone ( } 200 \mathrm{mg} / \text { day); sildenafil ( } 60 \mathrm{mg} / \text { day); metoprolol } \\
\text { (12.5 mg/day); torasemide ( } 5 \mathrm{mg} / \text { day); allopurinol (100 mg/day); } \\
\text { levothyroxine }(125 \mu \mathrm{g} / \text { day); ferric hydroxide (100 mg/day); } \\
\text { ursodeoxycholic acid ( } 900 \mathrm{mg} / \text { day) }\end{array}$ \\
\hline Antiviral medication & $\begin{array}{l}\text { 2015: one dose of sofosbuvir } 400 \mathrm{mg} \text { and ledipasvir } 60 \mathrm{mg}\left(\text { Harvoni }^{\circledR}\right) \text {; } \\
\text { 2017: } 12 \text {-week therapy with elbasvir } 50 \mathrm{mg} \text { and grazoprevir } 100 \mathrm{mg} \\
\left(\text { Zepatier }^{\circledR}\right) \text {, SVR } 12\end{array}$ \\
\hline $\begin{array}{l}\text { Adverse events under } \\
\text { sofosbuvir/ledipasvir }\end{array}$ & $\begin{array}{l}\text { sinus arrest and AV block type II, bradycardia of } 30 \mathrm{bpm} \text {; temporary } \\
\text { pacemaker for } 3 \text { days; } 3 \text {-day hospitalization }\end{array}$ \\
\hline $\begin{array}{l}\text { Adverse events under } \\
\text { elbasvir/grazoprevir }\end{array}$ & episodes of palpitations without pathological ECG correlation \\
\hline
\end{tabular}

Table 2. Overview of the patient's laboratory results at different time points

\begin{tabular}{|c|c|c|c|c|c|c|c|c|}
\hline & $\begin{array}{l}\text { Initial } \\
\text { presentation }\end{array}$ & $\begin{array}{l}3 \text { months before } \\
\text { elbasvir/grazoprevir }\end{array}$ & $\begin{array}{l}2 \text { weeks of } \\
\text { treatment }\end{array}$ & $\begin{array}{l}4 \text { weeks of } \\
\text { treatment }\end{array}$ & $\begin{array}{l}6 \text { weeks of } \\
\text { treatment }\end{array}$ & $\begin{array}{l}9 \text { weeks of } \\
\text { treatment }\end{array}$ & $\begin{array}{l}\text { End of } \\
\text { therapy }\end{array}$ & SVR 12 \\
\hline \multicolumn{9}{|l|}{ Liver values } \\
\hline ALT, U/L & 33 & 124 & 27 & 23 & 26 & 20 & 24 & 19 \\
\hline AST, U/L & 49 & 128 & 32 & 35 & 35 & 33 & 35 & 32 \\
\hline Gamma-GT, U/L & 123 & 252 & 117 & 85 & 71 & 53 & 45 & 39 \\
\hline $\mathrm{AP}, \mathrm{U} / \mathrm{L}$ & 68 & 86 & 82 & 81 & 82 & 73 & 91 & 73 \\
\hline \multicolumn{9}{|l|}{ Kidney values } \\
\hline Creatinine, $\mu \mathrm{mol} / \mathrm{L}$ & 102 & 101 & 136 & 122 & 101 & 115 & 123 & 106 \\
\hline eGFR, mL/min & 73 & 73 & 51 & 58 & 72 & 62 & 57 & 68 \\
\hline \multicolumn{9}{|l|}{ Viremia } \\
\hline Quantit. RNA-PCR, IU/mL & $3,612,790$ & 381,378 & 16 & negative & $<15$ & negative & negative & negative \\
\hline
\end{tabular}

